
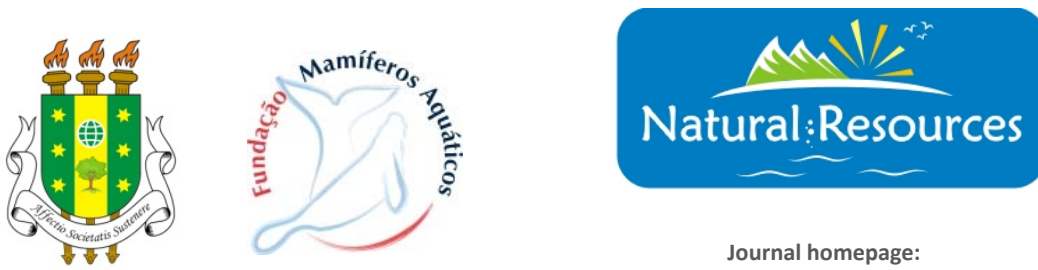

Journal homepage: www.arvore.org.br/see

\section{POSSIVEIS INTERAÇÕES DOS OURIÇOS-DO-MAR EM PRAIAS DO LITORAL SUL DE PERNAMBUCO, BRASIL}

\section{RESUMO}

Os costões rochosos apresentam elevada importância ecológica e podem conte alta riqueza de espécies. São locais de alimentação, crescimento e reprodução de diversos indivíduos. A intensa herbivoria é um dos principais fatores que afetam a abundância e distribuição de macroalgas nas comunidades marinhas. Foram realizadas incursões nas praias de Barra de Sirinhaém e Serrambi. As coletas foram feitas durante a maré baixa, na região de mesolitoral. As amostras foram identificadas, fotografadas. Foram observados que os ouriços estavam nos ecossistemas distribuídos nestas praias próximos a Caulerpa. Halimeda, Coralina, e Pterocladia, em Barra de Serrambi, Enteromorpha, Caulerpa e Ulva, em Barra de Sirinhaém. Nesta última foi identificado a presença de esponjas, aplysia sp, sendo esta alvos de manipulação por liberar secreção, também foram encontrados moluscos. Nestas praias principalmente em Barra de Serrambi, a presença humana foi muito marcante. Os organismos estavam muito vulneráveis, sendo observado manipulação, pisoteio e pesca do tipo predatória, que foi evidenciada também em Barra de Sirinhaém. Os dados aqui expostos sugerem a ocorrência de mecanismos de defesa presentes em macroalgas de diferentes táxons, e demais organismo, talvez em consequência da pressão ambiental frente aos eventos marinhos, possibilitando a criação de estratégias para a manutenção e sobrevivência harmônica das espécies.

PALAVRAS-CHAVE: Herbivoria; Organismos Marinhos; Ação Antrópica.
Natural Resources, Aquidabã, v.3, n.2, Set 2013.

ISSN 2237-9290

\section{SECTION: Anais do Congresso} Internacional de Ecotoxicologia Marinha (ECOMAR 2013)

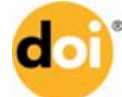

DOI: $10.6008 /$ ESS2237-9290.2013.002.0033

\section{Danilo Queiroz Viana}

Faculdade Frassinetti do Recife, Brasil http://lattes.cnpq.br/6251428672835036 danilo queirozviana@hotmail.com

Gilberto Henrique Teles Gomes da Silva

Faculdade Frassinetti do Recife, Brasil http://lattes.cnpq.br/1241778821756346

Inaldo Luiz Advíncula da Silveira Júnior

Faculdade Frassinetti do Recife, Brasil http://lattes.cnpq.br/5042239139116004 inaldo luizjr@hotmail.com

\section{José Ferreira da Silva Neto}

Universidade Federal Rural de Pernambuco, Brasil http://lattes.cnpq.br/1097116584108933 ferreirapeneto@hotmail.com

\section{Evandro Valentim da Silva}

Universidade Federal de Pernambuco, Brasil http://lattes.cnpq.br/0179071295238576 evandrovalentimblack@yahoo.com.br

Rita de Cássia Xavier de Carvalho Universidade de Pernambuco, Brasil http://lattes.cnpq.br/6232944501672764 ritacxcarvalho@hotmail.com

Received: 01/04/2013

Approved: $15 / 06 / 2013$

Reviewed anonymously in the process of blind peer.

\section{Referencing this:}

ALVES, R. C.; MARTINS, T.; CARRASCO, E. V. M. Possiveis interações dos ouriços-do-mar em praias do litoral sul de Pernambuco, Brasil. Natural Resources, Aquidabã, v.3, n.2, p.38, 2013. DOI: http://dx.doi.org/10.6008/ESS2237$\underline{9290.2013 .002 .0033}$ 